\title{
Southeast Asia - potential world food basket
}

\author{
W. J. van Liere
}

United Nations Economic and Social Commission for Asia and the Pacific (ESCAP), Bangkok 2, Thailand

Accepted: 3 October 1976

Keywords: Food production, multi-cropping, southeast Asia

\section{Summary}

It is suggested that southeast Asia has all the necessary prerequisite potentials in terms of land, water, year-round suitable climate and human resources to become a major world food basket. At the moment the level of production is rather low, as is demonstrated for a number of crops by comparing average farm yields with yields obtained under controlled conditions of the experimental stations in the area.

Mass application of modern technology, including water control and improvement of soil fertility, would be capable of closing the gap between present and potential production.

The programme of agricultural planning and research sponsored by the Mekong Committee represents a major initial step in this direction, aiming to bring about changes from traditional agricultural practices to progressively greater use of modern technology, tailored to suit local conditions, in order to achieve higher levels of sustained yield.

\section{The world food basket is shrinking}

Rapid growth of major population centres in both developed and developing countries after the second world was has greatly expanded world trade in basic foodstuffs and feed. Until now orderly world trade has been assured, more or less, by equally rapid growth of production in relatively small surplus production areas, where yields per unit area doubled or tripled through application of modern technology.

However, of all the surplus areas only one has remained in recent years as a major supplier in terms of annual volumes available for export and as a stabilizer in terms of stocks kept to blunt the effect of crop failures in other parts of the globe. This is the area covered by the Great Plains of the United States, and to a lesser extent Canada, which at present supplies annually 40 million tons of wheat, 30 million tons of maize and 15 million tons of soy beans for the world market. The Great Plains have become, in a sense, the surplus food basket of the world.

But there are valid reasons to doubt whether the Great Plains can fulfil this role 


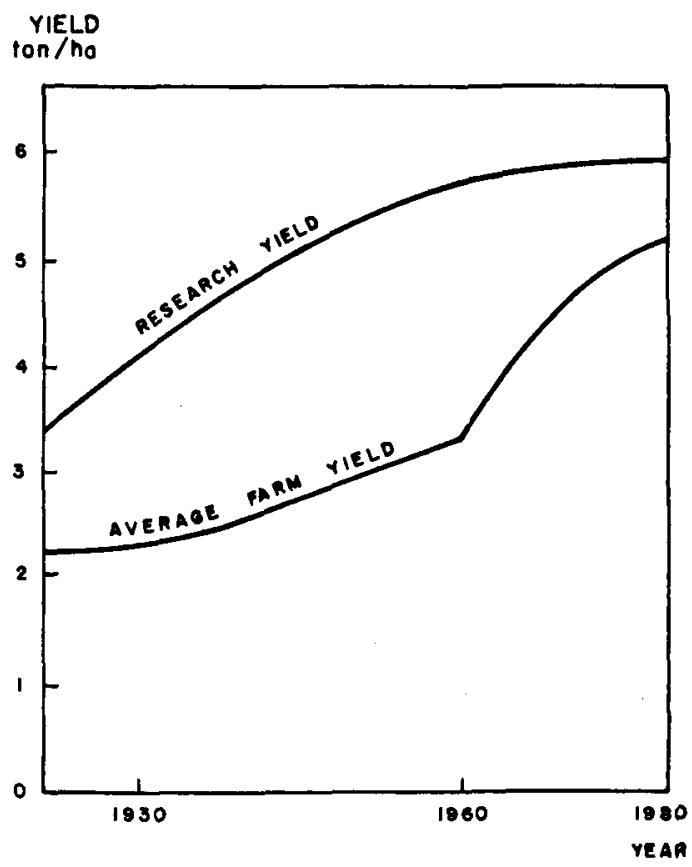

Fig. 1. Schematic presentation of maize yields on experimental plots compared to average farm yields in the great plains of the USA (after Thompson, 1975).

much longer. Farmers in the Great Plains have rapidly absorbed new agricultural technology, thus closing the gap between average farm yields and 'research yields', i.e. the potential maximum yields the farmers should be able to achieve with practical application of known advanced technology. In fact this gap is now very small and it is difficult to see how the Great Plains could again double their output over the next 30 years to maintain its position as the main food supplier for the world (Thompson, 1975; Fig. 1). Two more factors strengthen this doubt. Firstly, weather, rather than technology, will probably become the limiting factor in grain production at higher latitudes. Some climatologists assume even that the world may be heading for a period of greather weather oscillations, hence the prospects in that regard are far from encouraging. Secondly, the surplus grain producing areas employ a highenergy type of agriculture, and developments over the past several years have proved that energy is not limitless and instead will be a limiting factor affecting virtually all major enterprises in the future. Since, apart from untold human suffering, any disruption of the orderly world trade in basic foodstuffs tends to produce economic shock waves on a global scale, the conclusion must be that it is of great ungency to develop one or more additional surplus food baskets.

\section{Southeast Asia, potential second surplus food basket for the world}

Hypothetically, there should be no problem in developing additional major world food baskets. With present technology the world could produce the equivalent of 
many times the present cereal crop. This is the conclusion of a recent study which analyses potential productivity of current agricultural crops on arable lands and potentially cultivable lands identifiable on the FAO/UNESCO soil map of the world, with present rainfall patterns and gross photosynthesis (Buringh et al., 1975). However this analysis does not take into account institutional and other human constraints. Past experience and common sense exclude large areas of the world from being considered as major surplus producers in the near future. However, the plains and deltas of the major rivers of southeast Asia seem to have all of the basic characteristics to fulfil this role.

Actually the deltas of southeast Asia have already played the role of surplus producers of food for a long time. From the last century until the second world war, each of the major deltas in southeast Asia produced an annual rice surplus between one and three million tons. This was achieved in an almost non-monetized society, without any investment resources for on-farm development, merely by opening up the deltas with a network of canals. Since the second world war, some of the upland terraces have also been made accessible by a network of roads and, here again, we observe immediately the production of a large surplus of upland crops.

The rural areas of mainland southeast Asia are not yet over-populated. Farm size is still generally at the maximum a family can manage, that is from 2 to 4 ha. Only in a few areas is the farm size smaller than 2 ha. Traditionally, these small family farms have produced a surplus. Before the second world war, the export surplus of paddy was between 40 and $50 \%$ of the total production (the highest being $65 \%$ in 1934-35). After the second world war this surplus dropped to between 20 and $30 \%$, not because of increase of home consumption, but because opportunities, other than growing rice, such as off-farm work and growing upland crops, became available. At present there is a marked shift of population from the rice growing areas to the upland areas.

These changes took place with traditional methods of growing crops and were generated by economic opportunities alone. Thailand can be taken as an example showing how rapidly the southeast asian agrarian economy can react to economic opportunities (Table 1).

The value of Thailand's export of agricultural produce, of which these new crops now constitute a major portion, stands at 2 billion dollars annually and is still growing. These crops are grown with minimum mechanical power and fertilizers.

Table 1. Changes in land use in Thailand from 1963 to 1973 for selected upland crops (in ha).

\begin{tabular}{lrrr}
\hline & \multicolumn{1}{c}{1963} & \multicolumn{1}{c}{1973} & Change (\%) \\
Forests (undifferentiated) & 27000000 & 20000000 & -26 \\
Paddy & 7000000 & 8000000 & +14 \\
Maize & 300000 & 1000000 & +265 \\
Cassava & 100000 & 500000 & +400 \\
Mung beans & 50000 & 200000 & +300 \\
Sugar cane & 72000 & 260000 & +260 \\
\hline
\end{tabular}


This proves that the small tropical farm can produce, at least initially, a large surplus with low energy inputs.

This is only the beginning. The potential which can be realistically envisioned for food production in southeast Asia is of an entirely new dimension compared with present practices. Water control supplementary to water transportation, accelerated on-farm development, high-yielding varieties and chemical fertilizers are all new technologies eminently suitable for southeast Asian farmers. At present farm yields are many times lower than research yields obtained in experimental farms in Asian countries. The next step will be to arrive at application of the new technology to supersede the present practices, which will yield a great increase in productivity. Even then, the potential of the small tropical farm will not have been reached. The available year-round sun energy allows multi-cropping on a continuing basis.

\section{Closing the gap between research and farm yields}

The research yield farm yield gap is illustrated in Fig. 2, 3 and 4 for paddy, maize and soy beans in Thailand. An analysis carried out by the International Rice Research Institute (IRRI) in the Philippines showed that for the lowlands lack of water control is the major factor limiting paddy production, not lack of enough basic rainfall nor inadequate soil fertility nor other factors. Because much of the paddy fields are rainfed and because much of the irrigated areas still suffer moisture stress during part of the growing season, farm yields are as low as one to two tons per ha (Herdt \& Wickham, 1974). Six tons per ha has been shown to be an attainable farm yield level.

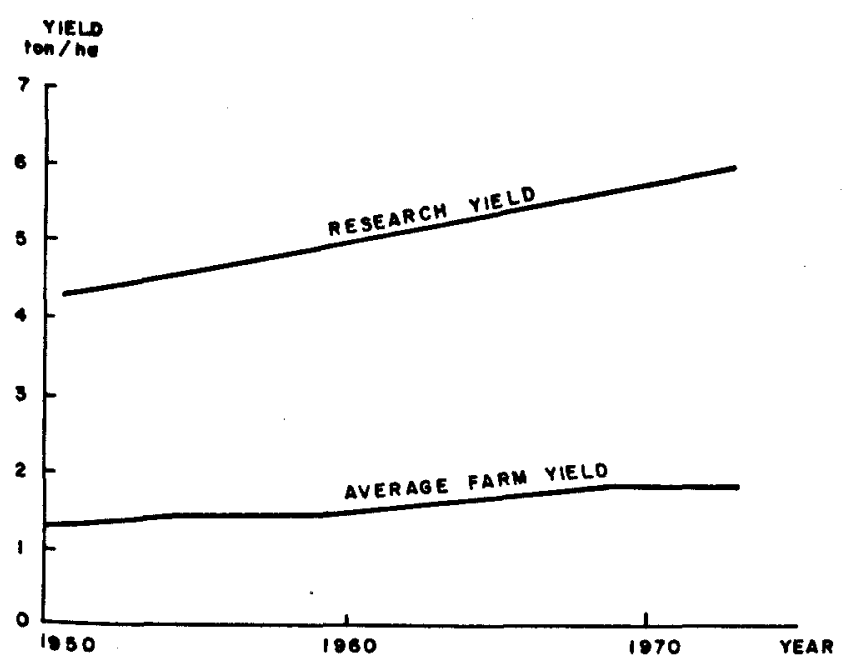

Fig. 2. Research and average farm yields of paddy in Thailand (wet season). 


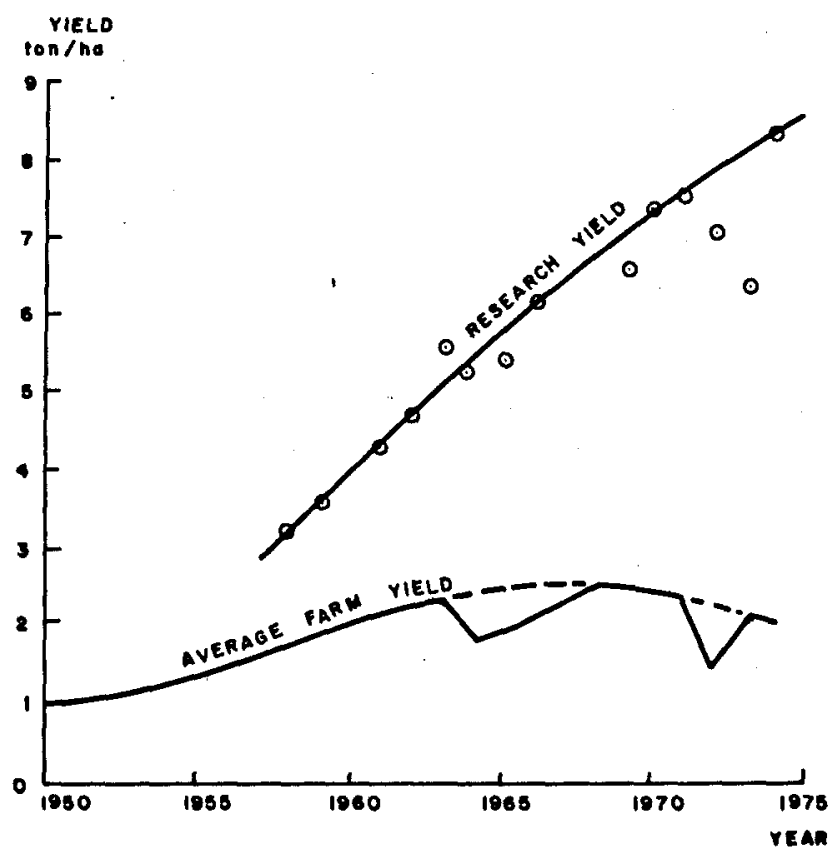

Fig. 3. Research and average farm yields of maize in Thailand.

For upland crops such as maize and soy beans, soil fertility plays a much larger role than for paddy, although moisture stress may in some cases also be a constraint. In Thailand, yields of 6 tons of maize per ha are obtained by applying large amounts of fertilizers, up to $500 \mathrm{~kg}$ of mixed fertilizers at seed-bed preparation $(16 / 20 / 0)$, supplemented by a top dressing of $300 \mathrm{~kg}$ of ammonium sulphate.

It is clear, therefore, that the yield gap can be closed in the tropics, but only with heavy investments in water control systems and through application of large amounts of chemical fertilizers. Unless these prerequisites are provided, the gap will continue to exist and probably will widen.

\section{The tropical two-hectare farm and 'low energy' agriculture}

In the tropics it is feasible to produce much more than one crop per year by means of multi-cropping. These intensively cultivated areas, employed especially for growing fruits and vegetables, lie primarily in the vicinity of large cities. The method, the 'raised bed' system, is in vogue in the deltas of the Chao Phya and the Mekong. In its more intensive form the 'raised bed' system achieves production worth about US\$1500/ha.

Research at IRRI has demonstrated (Bradfield, 1972) that by means of a modified furrow system, field crops can be grown jointly inter-cropped with rice throughout the year. The figures in Table 2 are from Bradfield (1972); the estimates of 
Table 2. Yields under intensive multiple cropping (after Bradfield, 1972).

\begin{tabular}{lcrl}
\hline Crop & Yield (tons/ha) & Yield $\left(\mathrm{J} / \mathrm{m}^{2}\right)$ \\
& & & \\
Rice & 4 & 4 & $\times 1465=5860$ \\
Sweet potato & 15 & $15 \times 480=7200$ \\
Sweet corn & 5 & $5 \times 1500=7500$ \\
Sorghum & 4.5 & $4.5 \times 1480=6660$ \\
Soya green & 3 (pods) & $3 \times 125=375$ \\
Soya mature & 1.25 & $1.25 \times 1590=1987$ \\
Cabbage & 12.5 & $12.5 \times 110=1375$ \\
\hline
\end{tabular}

caloric value were given by the author. Hence, total production per ha and per year was $18 \times 10^{n} \mathrm{~J}$. The total value of the crops amounted to US\$2500 per ha at 1972 prices. This was achieved on a 2-ha farm with a small six horse-power hand tractor with selected attachments, under simulated family farm conditions. Through this cropping system, as many as 450 crop days can be obtained per calendar year. No sophisticated farm technology other than improved management is involved and, if the means of production were readily available, this system could be applied in southeast Asia, although Bradfield's results were obtained under ideal conditions prevailing at the IRRI research station.

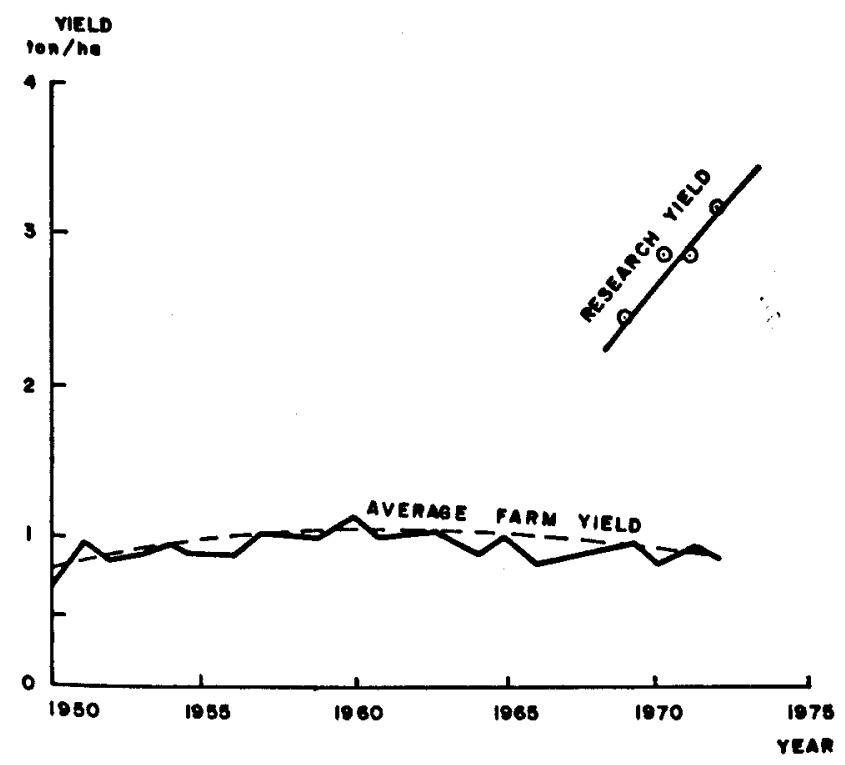

Fig. 4. Research and average farm yields of soya in Thailand. 


\section{Agricultural resources of southeast Asia}

Soil

The tropical soils of southeast Asia are in general not particularly fertile. Most of the upland soils are derived from acid igneous rocks or from sandstones, while the lowland soils are predominantly heavy acid clays. Moreover, many of the upland

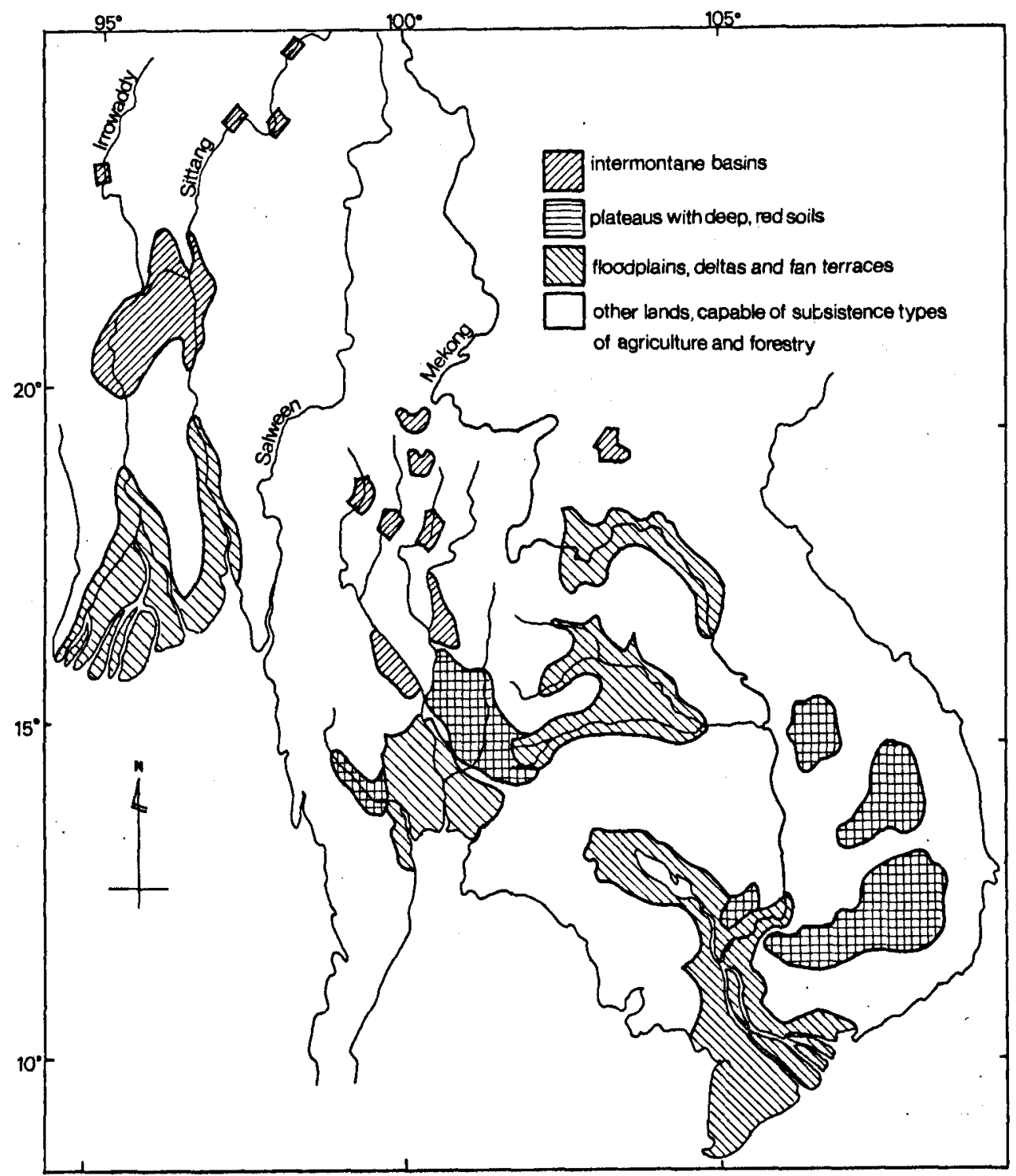

Fig. 5. Sketch map showing fertile areas in southeast Asia which are not over-populated. 
plains and plateaus are geologically old surfaces in various stages of laterization. However, there are exceptions to this general rule: sizeable areas of plateau basalts and limestones have soils eminently suitable for a large variety of crops; in the flood plains, too, the natural productivity of fresh alluvials is high. Thus, in spite of the relatively poor fertility of most of the soils, southeast Asia has some 25 million ha of good agricultural land, suitable for intensive cropping (Fig. 5). These include intermontane basins in upper Burma, northern Thailand and Laos; flood plains, deltas and fan terraces of the Irrawaddy, Chao Phya and Mekong and their tributaries, as well as sizeable plateaus with deep, red soils in upper Burma, Thailand, Laos, Cambodia and Vietnam.

\section{Climate}

The climate features monsoon rainfall patterns very much related to topography. The southwest monsoon brings in humid air from the Indian Ocean between May and October. Rainfall is particularly heavy along the west flanks of the north-south mountain ranges. Most of the plains and lowlands to the east and between these mountain ranges are in rain shadows. Rainfall in the hills and on the western flanks runs as high as 3000 to $5000 \mathrm{~mm}$ per year, while in the plains and lowlands it is 800 to $1600 \mathrm{~mm}$ per year. Almost all the rain falls between May and October.

Annual fluctuation in total rainfall and its distribution throughout the rainy season cause yield depressions of the major crops every year, but the climatic oscillations are never so great as to cause overall crop failures. In this respect, southeast Asia is favoured over sub-tropical and boreal food producing regions.

\section{Water}

The primary major agricultural asset of southeast Asia, in addition to its climate, lies in its water resources. Annually $10^{12}$ cubic metres of water run unused to the sea. Since monsoon rivers behave erratically, much damage is done by flooding during the wet season. Yet, excellent dam sites exist on all major rivers, and stream regulation is a feasible solution with present technology. The water stored by the dams would not only permit irrigation of the downstream lowlands; it could also generate huge amounts of power, part of which could be used indefinitely for the production of fertilizers.

\section{Where to begin - the case for the lower Mekong basin as a development model}

The four riparian countries of the lower Mekong basin have been working jointly towards the development of the water resources of the lower Mekong and its tributaries, with assistance from the United Nations and with the active cooperation of 25 countries and 15 international organizations. To this end a high-powered inter-governmental committee for coordination of investigations has been at work for almost twenty years to help meet current needs and lay the foundation for future development. One of the major aspects of its programme has been planning for the enhancement of agricultural productivity of the lower Mekong basin, taking advantage of the opportunities deriving from water resource development. The basic 
W. J. VAN LIERE

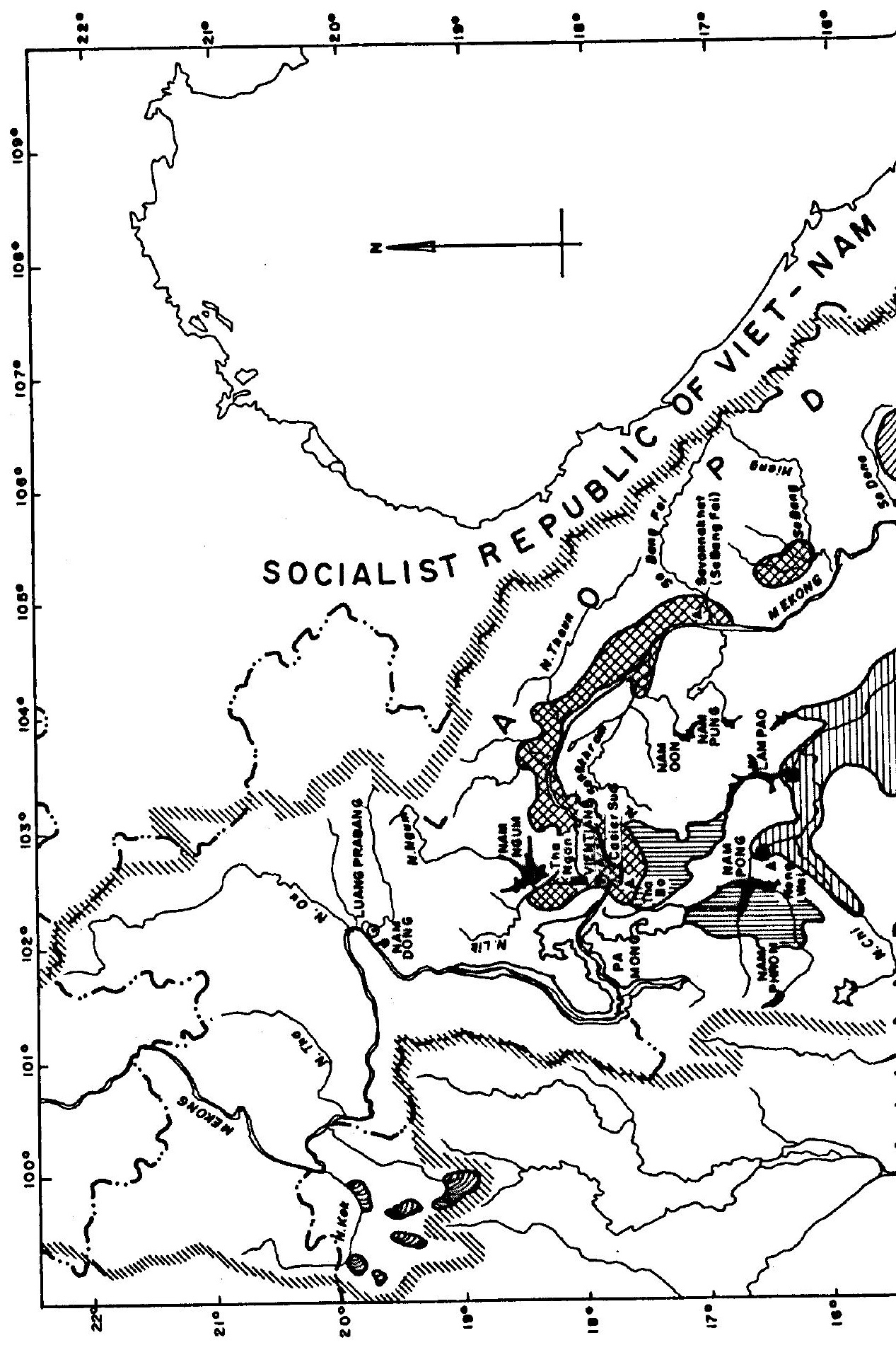


idea of this effort is gradual transformation of existing agricultural practices to create sustained yielding farm systems that will become feasible as a result of water control in its widest sense, taking into account the ecological and other constraints of the future.

An important aspect of this programme relates to agricultural experimentation and pioneer agricultural projects. The specific objective of the former is to experiment with new agronomic methods to test potential yields. The pioneer projects, in turn, would develop managerial practices, including water supply and control, operation and maintenance, farm unit development and necessary supplies and equipment under actual operational conditions in areas of 5000-10 000 ha. Thus the pioneer projects will serve to test and demonstrate the feasibility of new concepts of agriculture, beginning with smaller areas and progressing to ever larger areas as experience is gained, until eventually the new concepts are applied on a massive scale.

Much experience has already been gained with irrigation projects on the tributaries of the Mekong. It has become obvious that full water resources development requires major changes affecting nearly every segment of the rural society. It has also become clear that the present productive capacity of the lower Mekong basin is rather low compared with the needs of the anticipated future populations. Hence the food productivity of the lower basin must be increased if for no other reason than to meet the region's own future food needs. The important point, however, is that the potentials of the region are for production levels far exceeding these needs, so that the lower Mekong basin could truly become another world food basket. Water resources development is the key to increasing the existing carrying capacity.

\section{The Pa Mong project}

A very significant effort, which could be a major step in achieving the goal described above, is the proposed $\mathrm{Pa}$ Mong project. This would involve construction of a dam across the Mekong river between Thailand and Laos some $50 \mathrm{~km}$ upstream of Vientiane. The storage of the Pa Mong reservoir would be about $10^{11} \mathrm{~m}^{3}$ or $20 \%$ of the annual flow of the river. This reservoir would make it possible (Fig. 6): a) to virtually eliminate flooding along the middle course of the Mekong river, which is a zone of densely populated riverine lands and to develop these lands by low lift pump irrigation;

b) to irrigate large areas in northeast Thailand, a region sorely lacking in water and, through the irrigation system, supply thousands of villages with domestic water as well;

c) to transfer some $5 \times 10^{9} \mathrm{~m}^{3}$ of surplus water, that cannot be used elsewhere, to the central plain in Thailand;

d) to reclaim some 200000 ha in Cambodia through flood regulation and to convert another 200000 ha of flood lands, now used for floating rice into highly productive transplant rice;

e) to make available about $30 \times 10^{9} \mathrm{~m}^{3}$ of fresh water throughout the dry season 
to the delta lands in Vietnam, an area equally lacking in fresh water in the dry season; and

f) to engage in fish farming throughout the lower Mekong basin on a sustained yearround basis.

In addition the $\mathrm{Pa}$ Mong project could generate huge amounts of power, for which there is a ready market, resulting in revenues which can be used in part to finance the vast new agricultural enterprise, and to help solve many other urgent regional problems including the achievement of realistic programmes for conservation of forests and wildlife.

Developments such as planned for Pa Mong will radically change the economic horizons of southeast Asia.

\section{Modernization, a blessing or a curse?}

Technology can be blessing or a curse. If applied rationally, its benefits are boundless; if misused, it may destroy the basic resources of the earth. There are numerous examples of civilizations that have crumbled because of misuse of technology. Perhaps we are witnessing a repetition today. Forests are disappearing at an incredible rate due to mechanized tree felling; soils become exhausted because of over-cultivation without fertilizers; waters become depleted because of over-fishing; wildlife becomes extinct because of hunting with modern weapons. Changes are so rapid in southeast Asia that their effect is always under-estimated because each observation is outdated by reality.

It would appear that the only way to reverse the accelerating trend is through a massive development programme. The obvious focus for the initial effort would be the lower Mekong basin for which almost twenty years of data gathering, analysis and planning have been completed. Thus, the development of the basin could not only become a blessing for its inhabitants; its effect could be worldwide, since it could lead the way towards transforming southeast Asia into a sustained yielding world food basket.

\section{References}

Bradfield, R., 1972. Maximizing food production through multiple cropping system centered on rice. In: Rice, science and man, IRRI, Los Baños, Philippines.

Buringh, P. et al., 1975. Computation of the absolute maximum food production of the world. Agricultural University, Wageningen, the Netherlands.

Herdt, R. W. \& T. H. Wickham, 1974. Exploring the gap between potential and actual rice yields in the Philippines. Agriculture Economics Department, IRRI, Los Baños, Philippines.

Thompson, L. M., 1975. Weather variability, climatic change and world food supplies. American Association of Agricultural Science, New York. 